Review

\title{
Biotechnological wound dressings based on bacterial cellulose and degradable copolymer $\mathrm{P}(3 \mathrm{HB} / 4 \mathrm{HB})$
}

\author{
T.G. Volova a,b ${ }^{\text {, A.A. Shumilova }}{ }^{\text {a,* }}$, E.D. Nikolaeva ${ }^{\text {b }}$, A.K. Kirichenko ${ }^{\text {c }}$, E.I. Shishatskaya ${ }^{\text {a,b }}$ \\ a Siberian Federal University, 79 Svobodnyi Av., Krasnoyarsk 660041, Russia \\ b Institute of Biophysics of Siberian Branch of Russian Academy of Sciences, Akademgorodok, Krasnoyarsk 660036, Russia \\ c V.F. Voino-Yasenetsky Krasnoyarsk State Medical University, 1 Partizan Zheleznyak Street, Krasnoyarsk 660022, Russia
}

\section{A R T I C L E I N F O}

\section{Article history:}

Received 10 December 2018

Received in revised form 29 January 2019

Accepted 10 March 2019

Available online 12 March 2019

\section{Keywords:}

Bacterial cellulose

Polyhydroxyalkanoates

Composites

\begin{abstract}
A B S T R A C T
Hybrid wound dressings have been constructed using two biomaterials: bacterial cellulose (BC) and copolymer of 3-hydroxybutyric and 4-hydroxybutyric acids [P(3HB/4HB)] - a biodegradable polymer of microbial origin Some of the experimental membranes were loaded with drugs promoting wound healing and epidermal cells differentiated from multipotent adipose-derived mesenchymal stem cells. A study has been carried out to investigate the structure and physical/mechanical properties of the membranes. The in vitro study showed that the most effective scaffolds for growing fibroblasts were composite $\mathrm{BC} / \mathrm{P}(3 \mathrm{HB} / 4 \mathrm{HB})$ films loaded with actovegin. Two types of the experimental biotechnological wound dressings - $\mathrm{BC} / \mathrm{P}(3 \mathrm{HB} / 4 \mathrm{HB}) /$ actovegin and $\mathrm{BC} / \mathrm{P}(3 \mathrm{HB} /$ $4 \mathrm{HB}$ )/fibroblasts - were tested in vivo, on laboratory animals with model third-degree skin burns. Wound planimetry, histological examination, and biochemical and molecular methods of detecting factors of angiogenesis, inflammation, type I collagen, and keratin 10 and 14 were used to monitor wound healing. Experimental wound dressings promoted healing more effectively than VoskoPran - a commercial wound dressing.
\end{abstract}

(c) 2019 Elsevier B.V. All rights reserved.

\section{Contents}

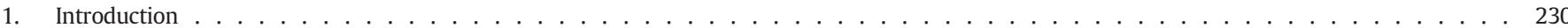

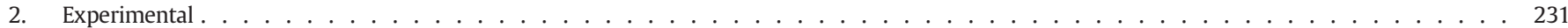

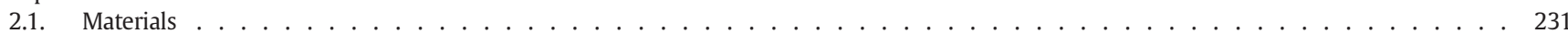

2.2. Constructing $\mathrm{BC} / \mathrm{P}(3 \mathrm{HB} / 4 \mathrm{HB})$ composites as wound dressings. . . . . . . . . . . . . . . . . . . . . . . . . . . 231

2.3. A study of the structure and physical properties of $\mathrm{BC} / \mathrm{P}(3 \mathrm{HB} / 4 \mathrm{HB}) \ldots \ldots \ldots \ldots$

2.4. Loading of cells and wound-healing drugs into BC/P(3HB/4HB) composites. . . . . . . . . . . . . . . . . . . . . . . . 232

2.5. A study of biological compatibility of $\mathrm{BC} / \mathrm{P}(3 \mathrm{HB} / 4 \mathrm{HB})$ composites in cell culture . . . . . . . . . . . . . . . . . . . . . . . . . 232

2.6. An in vivo study of $\mathrm{BC} / \mathrm{P}(3 \mathrm{HB} / 4 \mathrm{HB})$ composites and hybrids as experimental wound dressings . . . . . . . . . . . . . . . . . . . . . . 232

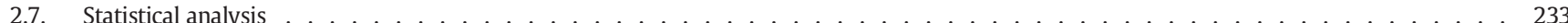

3. Results and discussion . . . . . . . . . . . . . . . . . . . . . . . . . . . . . . . . 233

3.1. Production and properties of $\mathrm{BC} / \mathrm{P}(3 \mathrm{HB} / 4 \mathrm{HB})$ hybrids $\ldots \ldots \ldots \ldots \ldots$

3.2. Biological properties of $\mathrm{BC} / \mathrm{P}(3 \mathrm{HB} / 4 \mathrm{HB})$ hybrids . . . . . . . . . . . . . . . . . . . . . . . . . . 235

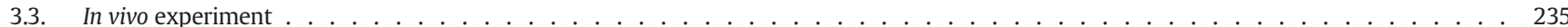

4. Conclusion . . . . . . . . . . . . . . . . . . . . . . . . . . . . . . . . . . . . . . . . . 239

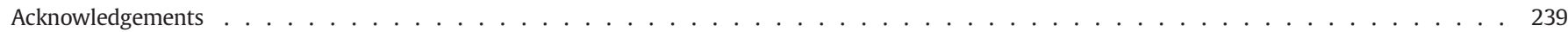

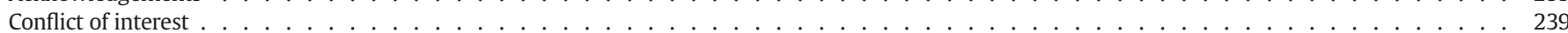

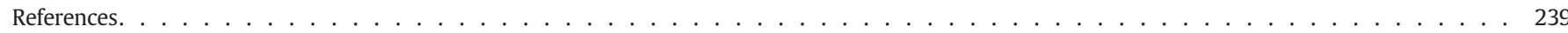

\footnotetext{
* Corresponding author.

E-mail address: shumilova.ann@mail.ru (A.A. Shumilova).
}

\section{Introduction}

Facilitating skin wound healing by using new technologies and materials is one of the main challenges facing science and clinical practice. 
Hundreds of surgical and therapeutic materials and tools can be used to reconstruct skin defects. Considerable research effort is being placed on natural and synthetic polymers (derivatives of methyl methacrylate, dextran, acrylamide, agar-agar, etc.) [1]. These materials are used to produce sponges, film coatings, and gel-forming coatings, which can be applied in Phases II and III of the healing process [2].

The properties of the material used to fabricate wound dressings must correspond to the type of the injury and to the development and phase of the healing process. Fabrication of biotechnological dermal equivalents carrying cells is a rapidly developing line of research aimed at reconstructing skin defects. The main challenge facing researchers is the choice of materials, which should have a number of special properties and impart characteristics of living tissues to the engineered constructs (grafts). These characteristics include 1) the ability to regenerate themselves, 2) the ability to maintain the blood supply, and 3 ) the ability to alter their structure and properties in response to effects of the external factors, including mechanical loads [3].

Bacterial cellulose (BC) and bioresorbable polyhydroxyalkanoates (PHAs) are promising materials for reconstructive biomedical technologies including tissue engineering. BC shows high biocompatibility, without being cytotoxic or causing any allergic reactions in vivo; it has unique structure and physical/mechanical properties including high mechanical strength, elasticity, gas permeability, good water holding capacity, porosity, etc. The BC structure and high biocompatibility suggest that this natural polymer can be useful for reconstructive surgery as material for skin defect reconstruction and as a matrix for drug delivery [4-9].

A number of studies showed the effectiveness of using BC alone and $\mathrm{BC}$ composites with various materials in reconstructing skin defects. Cellulose impregnated with lidocaine considerably facilitated healing of third-degree burns [7]. Full-thickness skin wounds in rats healed effectively under a film of BC nanocrystals/chitosan incorporating silver and curcumin particles [10]. BC scaffolds with curcumin particles encapsulated in chitosan and in composition with gelatin and fibrin were used to manage skin wounds in mice and rats [11-13]. Singla et al. [14] investigated hydrogels prepared from bamboo cellulose nanocrystals loaded with silver particles, which successfully healed skin wounds in diabetic mice. Other authors tested gels based on cellulose and acrylate loaded with fibroblasts and keratinocytes, which considerably accelerated the healing of model burns and synthesis of type 1 collagen $[15,16]$.

$\mathrm{P}(3 \mathrm{HB} / 4 \mathrm{HB})$ is one of the most attractive representatives of polyhydroxyalkanoates (PHAs). PHAs are biopolymers of microbial origin, which are biodegradable, highly biocompatible, and effective in various biomedical applications. PHAs have been successfully tested as resorbable surgical sutures [17], artificial pericardium [18], wound dressings [19], implants for repairing cranial defects [20], biocompatible coatings for metallic stents [21], fully resorbable stents [22], biliary stents [23], etc. [24-26]. Thus, each of these biomaterials (BC and PHA) can be used to regenerate tissues, including skin.

One of the new lines of research is constructing composite materials and implants based on BC and PHA to repair tissue defects. Preparation of the $\mathrm{BC} / \mathrm{PHA}$ composite materials and their characterization are described in a number of studies [27-32].

The purpose of the present study was to construct and investigate composites based on BC and PHA as biotechnological wound dressings and to evaluate their efficacy in managing model skin burns in experiments with laboratory animals.

\section{Experimental}

\subsection{Materials}

Bacterial cellulose films were synthesized in the Komagataei bacterxylinus B-12068 culture. The strain was isolated from the fermented tea (kombucha) Medusomyces gisevii J. Lindauon HestrinSchramm (HS) medium. The strain was identified based on its morphological, biochemical, genetic, and growth parameters. The strain
Komagataeibacter xylinus was deposited in the Russian National Collection of Industrial Microorganisms (VKPM) with registration number VKPM B-12068. The collection culture of K. xylinus B-12068 was maintained on the Hestrin-Schramm (HS) agar medium. The standard HS medium contained $(\% w / v)$ : glucose -2 , peptone -0.5 , yeast extract $0.5, \mathrm{Na}_{2} \mathrm{HPO}_{4} 0.27$, and citric acid -0.115 . The pre-culture was performed on the HS agar. Then, the colonies were transferred into the flask containing liquid HS medium and cultivated for 7 days at a temperature of $30^{\circ} \mathrm{C}$ under static conditions. To remove remnants of bacterial cells and components of culture medium, BC films were treated with $1.0 \mathrm{M} \mathrm{NaOH}$ at $70{ }^{\circ} \mathrm{C}$, followed by washing in deionized water. The synthesized cellulose was separated from the culture fluid. Then, BC films were placed in a $0.5 \%$ solution of hydrochloric acid for $24 \mathrm{~h}$ for neutralization and, afterwards, rinsed in distilled water until $\mathrm{pH}$ 7. The BC films were stored in sterile solution or air dried until they reached a stable weight.

In the present study, PHA copolymers comprising monomers of 3hydroxybutyric and 4-hydroxybutyric acids $[\mathrm{P}(3 \mathrm{HB} / 4 \mathrm{HB})]$ were used. This is the best PHA for fabricating biomedical products: $\mathrm{P}(3 \mathrm{HB} / 4 \mathrm{HB})$ has a low degree of crystallinity, the highest elasticity, and the fastest rate of biodegradation in vivo. The polymer was synthesized in Cupriavidus eutrophus B10646 microbial culture (the strain is registered in the Russian Collection of Industrial Microorganisms) [31]. Cells were batch-cultured in a 14-L New Brunswick Scientific BioFlo 110 fermentor filled to $40 \%$ of its volume with standard mineral salt medium: $\mathrm{Na}_{2} \mathrm{HPO}_{4} \cdot \mathrm{H}_{2} \mathrm{O}-9.1 ; \mathrm{KH}_{2} \mathrm{PO}_{4}-1.5 ; \mathrm{MgSO}_{4} \cdot \mathrm{H}_{2} \mathrm{O}-0.2 ; \mathrm{Fe}_{3} \mathrm{C}_{6} \mathrm{H}_{5} \mathrm{O}_{7} \cdot 7 \mathrm{H}_{2} \mathrm{O}$ - $0.025 ; \mathrm{NH}_{4} \mathrm{Cl}-0.5(\mathrm{~g} / \mathrm{L})$; the medium was supplemented with glucose in amounts corresponding to cell concentration in the medium. A solution of iron citrate $(5 \mathrm{~g} / \mathrm{L})$ was used as a source of iron. Hoagland's trace element solution was used: $3 \mathrm{ml}$ of standard solution per $1 \mathrm{~L}$ of the medium. The standard solution contained $\mathrm{H}_{3} \mathrm{BO}_{3}-0.288$; $\mathrm{CoCl}_{2} \cdot 6 \mathrm{H}_{2} \mathrm{O}-$ $0.030 ; \mathrm{CuSO}_{4} \cdot 5 \mathrm{H}_{2} \mathrm{O}-0.08 ; \mathrm{MnCl}_{2} \cdot 4 \mathrm{H}_{2} \mathrm{O}-0.008 ; \mathrm{ZnSO}_{4} \cdot 7 \mathrm{H}_{2} \mathrm{O}-$ $0.176 ; \mathrm{NaMoO}_{4} \cdot 2 \mathrm{H}_{2} \mathrm{O}-0.050 ; \mathrm{NiCl}_{2}-0.008(\mathrm{~g} / \mathrm{L})$. In order to achieve synthesis of $\mathrm{P}(3 \mathrm{HB} / 4 \mathrm{HB})$ copolymer, the culture medium was supplemented with additional carbon substrate ( $\gamma$-butyrolactone).

\subsection{Constructing $B C / P(3 H B / 4 H B)$ composites as wound dressings}

Composites were prepared from BC films or powder and solutions of poly(3-hydroxybutyrate-co-4-hydroxybutyrate) [P(3HB/4HB)] (85 mol $\% 3 \mathrm{HB} / 15 \mathrm{~mol} \% 4 \mathrm{HB}) . \mathrm{BC} / \mathrm{P}(3 \mathrm{HB} / 4 \mathrm{HB})$ hybrids were constructed using different methods: 1 ) dried $\mathrm{BC}$ pellicles and wet (chloroform-impregnated) $\mathrm{BC}$ pellicles were soaked in $2 \%$ and $5 \% \mathrm{P}(3 \mathrm{HB} / 4 \mathrm{HB})$ solutions in chloroform; 2 ) dried $\mathrm{BC}$ pellicles were soaked in a $2 \% \mathrm{P}(3 \mathrm{HB} / 4 \mathrm{HB})$ solution in chloroform, kept there for $24 \mathrm{~h}$, and dried in a dust-free cabinet until the solvent had completely evaporated; 3 ) nonwoven membranes were placed into the K. xylinus B-12068 culture, and bacterial cellulose synthesized in it grew on the surface of the membranes under static conditions; 4 ) powdered cellulose (particle size of $120 \mu \mathrm{m}$ ) was added to a $3 \% \mathrm{P}(3 \mathrm{HB} / 4 \mathrm{HB})$ solution in chloroform and mixed ultrasonically to homogeneity; then, films were produced by the solvent evaporation technique, at polymer to cellulose ratios of $2: 1$ and $1: 1 ; 5) \mathrm{P}(3 \mathrm{HB} / 4 \mathrm{HB})$ powder was added to the K. xylinus B-12068 culture; and 6) a film of bacterial cellulose grew on nonwoven membranes in the submerged culture of K. xylinus B-12068.

\subsection{A study of the structure and physical properties of $B C / P(3 H B / 4 H B)$}

The thickness of composites was measured with a LEGIONER EDM25-0.001 electronic digital micrometer (Legioner, China); accuracy of measurement was $1 \mu \mathrm{m}$; surface properties were examined using a DSA-25E drop shape analyzer (Krüss, Germany) and software DSA-4 for Windows [34]. A minimum of six measurements were taken for each surface; means and standard deviations were calculated.

To study the surface of the sample more carefully, the investigation was carried out with a scanning electron microscope S-5500 (Hitachi, 
Japan) in the Center of the common use of Krasnoyarsk Scientific Center Siberian Branch of Russian Academy of Sciences. Prior to the analysis, the films were freeze-dried in an ALPHA 1-2/LD freeze dryer (Martin Christ $\mathrm{GmbH}$, Germany) for $24 \mathrm{~h}$. Samples $(5 \times 5 \mathrm{~mm})$ were placed onto the sample stage and sputter-coated with platinum, using an Emitech K575X sputter coater ( $10 \mathrm{~mA}, 2 \times 40 \mathrm{~s})$. Fiber diameters were measured by analyzing SEM images with image analysis program Image Processing and Data Analysis in Java (ImageJ). The diameters of 50 individual ultrafine fibers were then measured in each SEM micrograph. Diameters were analyzed in 10 fields of SEM images in triplicate.

The elemental composition of the $\mathrm{BC} / \mathrm{P}(3 \mathrm{HB} / 4 \mathrm{HB})$ was examined using scanning electron microscopy (a TM-3000 Hitachi microscope with the system QUANTAX 70 program).

Thermal analysis of samples was performed using a DSC-1 differential scanning calorimeter (METTLER TOLEDO, Switzerland). Powdered samples ( $4.0 \pm 0.2 \mathrm{mg}$ each) were placed into the aluminum crucible and compressed prior to measurement. Every sample was measured at least 3 times. Samples were preheated to $60{ }^{\circ} \mathrm{C}$ and cooled to $25^{\circ} \mathrm{C}$. The samples were heated to temperatures from $25^{\circ} \mathrm{C}$ to $300{ }^{\circ} \mathrm{C}$, at 5 ${ }^{\circ} \mathrm{C} \times \min ^{-1}$ (measurement precision $1.5^{\circ} \mathrm{C}$ ); melting point $\left(\mathrm{T}_{\mathrm{m}}\right)$ and thermal decomposition temperature $\left(T_{d}\right)$ were determined from exothermal peaks in thermograms. The thermograms were analyzed using the STARe v11.0 software.

$\mathrm{X}$-Ray structure analysis and determination of crystallinity of the BC composites were performed employing a D8 ADVANCE X-Ray powder diffractometer equipped with a VANTEC fast linear detector, using CuKa radiation (Bruker, AXS, Germany). In order to determine the crystallinity $\left(C_{x}\right)$ of $B C$, the spectra were collected from a $V_{\text {antec }}$ high-speed detector, with exposure time of 3000 . The detector was operated at $40 \mathrm{kV}$ and $40 \mathrm{~mA}$.

BC films were sterilized with $\mathrm{H}_{2} \mathrm{O}_{2}$ plasma in a Sterrad NX medical sterilizer (Johnson \& Johnson, U.S.) and investigated in cell culture assays.

\subsection{Loading of cells and wound-healing drugs into $B C / P(3 H B / 4 H B)$} composites

To prepare composites loaded with cells, 10-mm-diameter $\mathrm{BC} / \mathrm{P}$ (3HB/4HB) disks were placed into 24-well culture plates (TPP Techno Plastic Products AG, Switzerland) and sterilized in a Sterrad NX medical sterilizer (Johnson \& Johnson, U.S.). Fibroblasts were derived from the adipose tissue MSCs of Wistar rats. The adipose tissue cells were isolated enzymatically. The adipose tissue was rinsed in a DPBS solution with antibiotics, ground, and incubated in a type I collagenase solution (100 units $/ \mathrm{mL}$ ) at $37^{\circ} \mathrm{C}$ until tissue particles were dissolved, but for no more than $1 \mathrm{~h}$. Then, collagenase was inactivated with an albumin solution, centrifuged, and rinsed in the DMEM medium several times, until the lipid layer had been completely removed. The settled cells were suspended and seeded onto Petri dishes that contained the DMEM medium (Gibco) with $10 \%$ fetal bovine serum (HyClone) and a solution of antibiotics: penicillin, streptomycin, and Amphotericin B (Gibco). On the DMEM medium, adipose tissue cells showed fibroblast-like morphology. After 3-4 passages, the cells were removed from the Petri dishes with a trypsin solution (Gibco) and seeded onto sterile $\mathrm{BC} / \mathrm{P}(3 \mathrm{HB} / 4 \mathrm{HB})$ disks: $10^{5}$ cells per disk.

Loading of $\mathrm{BC} / \mathrm{P}(3 \mathrm{HB} / 4 \mathrm{HB})$ composites with drugs promoting wound healing was performed using solutions of actovegin (Takeda Pharmaceuticals, Russia) and solcoseryl (MEDA Pharma, Switzerland). Sterile composite samples were exposed to phosphate-buffered saline (PBS) to investigate drug release. Under aseptic conditions, the samples were placed into vials, each containing $50 \mathrm{~mL}$ saline at $\mathrm{pH}=6$. The vials were incubated in a thermostat for $72 \mathrm{~h}$ at a temperature of $37^{\circ} \mathrm{C}$. The experiment was done with samples $1 \mathrm{~cm}$ in diameter prepared with different percentages of drugs ( $1 \%-5 \%)$.
2.5. A study of biological compatibility of $B C / P(3 H B / 4 H B)$ composites in cell culture

$\mathrm{BC} / \mathrm{P}(3 \mathrm{HB} / 4 \mathrm{HB})$ samples loaded with drugs were shaped as $10 \mathrm{~mm}$ diameter disks. They were placed into 24 -well culture plates (TPP Techno Plastic Products AG, Switzerland) and sterilized in a Sterrad NX medical sterilizer (Johnson \& Johnson, U.S.). Scaffolds were seeded with cells at $10^{5}$ cells per scaffold for 7 days. Cells were cultured on the DMEM medium with $10 \%$ fetal bovine serum (HyClone) and a solution of antibiotics (Gibco reagents) in the $5 \% \mathrm{CO}^{2}$ atmosphere at $37^{\circ} \mathrm{C}$, with the medium replaced by the fresh one every three days. For MTT assay, 5\% MTT-bromid solution ( $50 \mu \mathrm{l})$ and complete nutrient medium $(950 \mu \mathrm{l})$ were added to each well of the culture plate. After $4 \mathrm{~h}$ cultivation, the medium and MTT solution were replaced by DMSO to dissolve MTT-formazan crystals. After dissolution of MTT-formazan crystals, 100 $\mu \mathrm{l}$ of supernatant was transferred to the 96-well plate, and optical density of the samples was measured at wavelength $540 \mathrm{~nm}$, using iMark microplate reader (Bio-Rad LABORATORIES Inc., U.S.). The number of viable cells was determined from the calibration graph.

2.6. An in vivo study of $B C / P(3 H B / 4 H B)$ composites and hybrids as experimental wound dressings

Experiments were conducted in accordance with Russian State Standard (GOST R ISO) 10993-1-2009 “Medical products. Estimating biological effects of medical products" and the international regulations International Guiding Principles for Biomedical Research Involving Animals (CIOMS, 1985), WMA Declaration of Helsinki on treating research animals with respect (2000), European Convention for the Protection of Vertebrate Animals used for Experimental and Other Scientific Purposes (Strasburg, 18.03.1986, ratification date 01.01.1991, CETS No. 123). The protocol of the experiments was approved by the Local Ethics Committee at the Siberian Federal University. The research animals were maintained and used in accordance with the rules accepted in the Russian Federation. The efficacy of the wound dressings based on BC and $\mathrm{P}$ (3HB/4HB) with and without fibroblasts differentiated from the adipose-derived MSCs was evaluated in experiments on research animals with model skin defects (burns) and compared to the efficacy of commercial wound dressings VoskoPran (Biotekfarm, Russia).

Sexually mature female Wistar rats were kept in the animal facility and fed their usual diet. The rats were anesthetized with $0.5-0.7 \mathrm{ml}$ of a $1 \%$ solution of sodium thiopental administered intraperitoneally. Then the animals were placed on their backs, and a $1 \mathrm{~cm}^{2}$ section of the skin was shaved. The burn was done with a 16-mm-diameter steel plate preheated in boiling water for $10 \mathrm{~min}$ to $100{ }^{\circ} \mathrm{C}$. The exposure lasted $8 \mathrm{~s}$ to create a second-degree skin burn (in accordance with ICD-10). After 5-10 min, the epidermis was separated from the underlying dermis with a sterile gauze swab. The animals were divided into 4 groups, 6 rats per group. In the treatment groups, three types of experimental wound dressings were used: $\mathrm{BC} / \mathrm{P}(3 \mathrm{HB} / 4 \mathrm{HB}), \mathrm{BC} / \mathrm{P}(3 \mathrm{HB} / 4 \mathrm{HB}) /$ actovegin, and $\mathrm{P}(3 \mathrm{HB} / 4 \mathrm{HB}) / \mathrm{BC} /$ fibroblasts. The dressings were fixed with single surgical sutures around wound edges. In the control group, the wounds were covered with polyamide mesh VoskoPran.

After the wounds were closed, each rat was placed in a separate cage for 14 days. The animals were euthanized with a lethal dose of Zoletil. Evaluation of the efficacy of the wound dressings was based on the intensity of the inflammatory response in the wound and surrounding soft tissues and the rate and completeness of skin repair.

Changes in the area of the wound surface were monitored by L.N. Popova's method [35], to determine the wound healing rate. At Days 3,7 , and 14 of the treatment, the animals were sacrificed and skin samples were removed and used in histology. Tissue layers with edges from the wound site were sectioned and fixed in a $10 \%$ formalin solution. The samples were processed by conventional procedure and embedded in paraffin. Histological sections were stained with hematoxylin and eosin. 
To get insight into the mechanism of the wound healing process, using molecular methods, we detected the factors that characterized the degree of inflammatory process, vascularization, and formation of the new connective tissue at the defect site: angiogenesis (VEGF), inflammation (TNF-a), type I collagen (Col-1) (an indicator of connective tissue formation), keratin 10 (K10), and keratin 14 (K14). Gene expression of type I collagen (Col-1) was determined by real time RT-PCR, to confirm the fibroblast phenotype of the cells and their viability. The cells were lysed, and mRNA was extracted using an RNA-Extran reagent kit (Sintol, Russia). The cDNA was synthesized by reverse transcription reaction using MMLV reverse transcriptase (Sintol, Russia). RT-PCR was performed with the corresponding primers using a Real-time CFX96 Touch detection system (Bio-Rad LABORATORIES Inc., U.S.) following the manufacturer's instructions. The housekeeping gene was $\beta$-actin. The comparative threshold cycle method $(2-\Delta \Delta \mathrm{Ct})$ was used to determine the relative level of expression of the marker genes. Total RNA was isolated from the granulation tissue of the treatment and control groups by extraction with a guanidinium thiocyanatephenol-chloroform mixture from the RNA-Extran reagent kit. Then, from the RNA template, using reverse transcriptase, we synthesized cDNA with several types of oligonucleotide primers: with a mixture of random primers - hexa primers - and oligo-dT primer, following the procedure recommended by the manufacturer (Sintol). Negative controls of reverse transcription reaction were prepared for all samples, to confirm the absence of DNA contamination in the initial RNA. Realtime PCR-amplification for quantification of cDNA fragments of rat VEGF, rat TNF-a, rat Col-1, rat K10, and rat K14 was performed by using a CFX-96 thermocycler, according to the manufacturer's protocol, using the color channel of HEX.

\subsection{Statistical analysis}

Statistical analysis of the results was performed using electronic tables in Microsoft Excel 2010 and the Statistica 6.0 program for the Windows XP operating system. Comparison of two related groups for quantitative attributes was performed using the parametric method with the Wilcoxon matched pairs test. Comparison of two independent groups for quantitative attributes was performed using the nonparametric method with the Mann-Whitney $U$ test. If the probability was greater than $95 \%$, the differences were considered as statistically significant.

\section{Results and discussion}

\subsection{Production and properties of $B C / P(3 H B / 4 H B)$ hybrids}

Composites based on $\mathrm{BC}$ and $\mathrm{P}(3 \mathrm{HB} / 4 \mathrm{HB})$ were constructed using different methods. Photographs of the samples are shown in Fig. 1 and SEM images in Fig. 2.

Samples prepared by adding nonwoven $\mathrm{P}(3 \mathrm{HB} / 4 \mathrm{HB})$ membranes and $\mathrm{BC}$ powder to the culture of acetic acid bacterium and samples produced by impregnation of $\mathrm{BC}$ films with a $5 \%$ solution of $\mathrm{P}(3 \mathrm{HB} / 4 \mathrm{HB})$ had no distinct structure and showed poor mechanical properties (Table 1).

The $\mathrm{BC} / \mathrm{P}(3 \mathrm{HB} / 4 \mathrm{HB})$ composites prepared by submerging nonwoven membranes into the K. xylinus B-12068 culture had the highest mechanical strength (Young's modulus of $272.3 \pm 27.2 \mathrm{MPa}$ ). The most likely reason for this is the high mechanical strength of the nonwoven membranes ( $113.54 \pm 9.85 \mathrm{MPa})$. The values of Young's modulus of the composites prepared by soaking $\mathrm{BC}$ films in the $2 \% \mathrm{P}(3 \mathrm{HB} / 4 \mathrm{HB})$ solution were 115 and $146 \mathrm{MPa}$, and they were higher than Young's modulus of the initial $\mathrm{P}(3 \mathrm{HB} / 4 \mathrm{HB})$ film. Although Young's modulus of the composites prepared by mixing the polymer solution and $\mathrm{BC}$ powder was low, it was higher than the corresponding parameter of pure $B C$ $(47.60 \pm 6.32 \mathrm{MPa})$, but elongation at break of the $\mathrm{P}(3 \mathrm{HB} / 4 \mathrm{HB})+\mathrm{BC}$ powder (1:1) (2:1) composites (3.45 $\pm 0.34 \%)$ was insignificantly lower than elongation at break of the initial BC film $(4.35 \pm 0.82 \%)$. The data reported in a number of studies suggested that $\mathrm{BC} / \mathrm{P}(3 \mathrm{HB} /$ $4 \mathrm{HB}$ ) composites prepared using different methods had better mechanical properties than pure BC. In a study by Zhijiang et al. [31], the mechanical properties of the nonwoven fiber based on P3HB and cellulose acetate produced by electrospinning were better than the mechanical properties of the nonwoven fiber based on cellulose acetate. With PHB content increasing from $60 \%$ to $90 \%$ in the blend nanofiber, the tensile strength, elongation at break, and Young's modulus increased from $4.52 \pm 0.34 \mathrm{MPa}, 6.53 \pm 0.48 \%$, and $806.9 \pm 168.2 \mathrm{MPa}$ to $7.86 \pm 0.67 \mathrm{MPa}, 16.7 \pm 1.52 \%$, and $854.2 \pm 187.6 \mathrm{MPa}$, respectively. In a study by Akaraonye et al. [29], the compressive modulus of porous composites based on P3HB was $0.08 \pm 0.01 \mathrm{MPa}$, but the addition of microfibrillated cellulose $(10,20,30$, and $40 \mathrm{wt} \%)$ increased it by $35 \%$, $37 \%, 64 \%$, and $124 \%$, respectively.

$\mathrm{BC} /$ poly(3-hydroxybutyrate) (PHB) composites with different PHB contents (25-90 wt\%) were prepared by Barud et al. [27] from BC
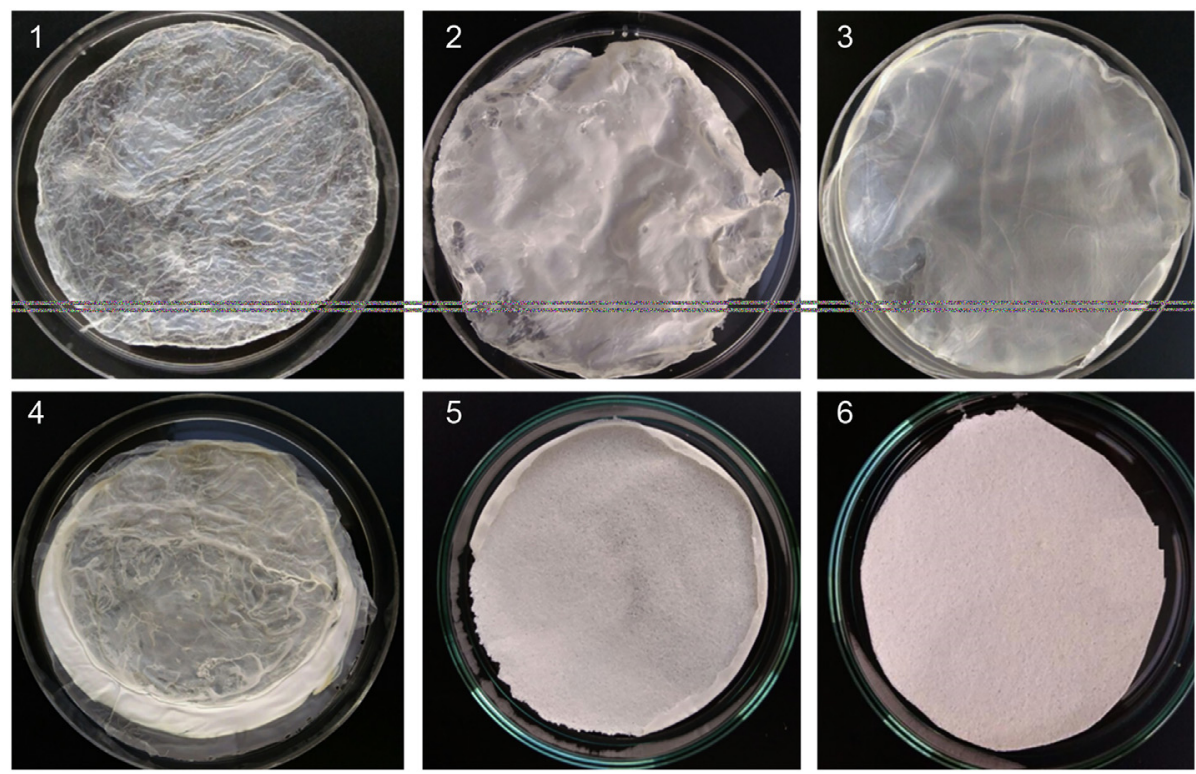

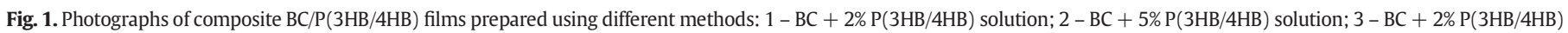
solution, soaked for $24 \mathrm{~h} ; 4$ - wet $\mathrm{BC}+2 \% \mathrm{P}(3 \mathrm{HB} / 4 \mathrm{HB})$ solution; $5-\mathrm{P}(3 \mathrm{HB} / 4 \mathrm{HB})+\mathrm{BC}$ powder $(2: 1) ; 6-\mathrm{P}(3 \mathrm{HB} / 4 \mathrm{HB})+\mathrm{BC}$ powder $(1: 1)$. 

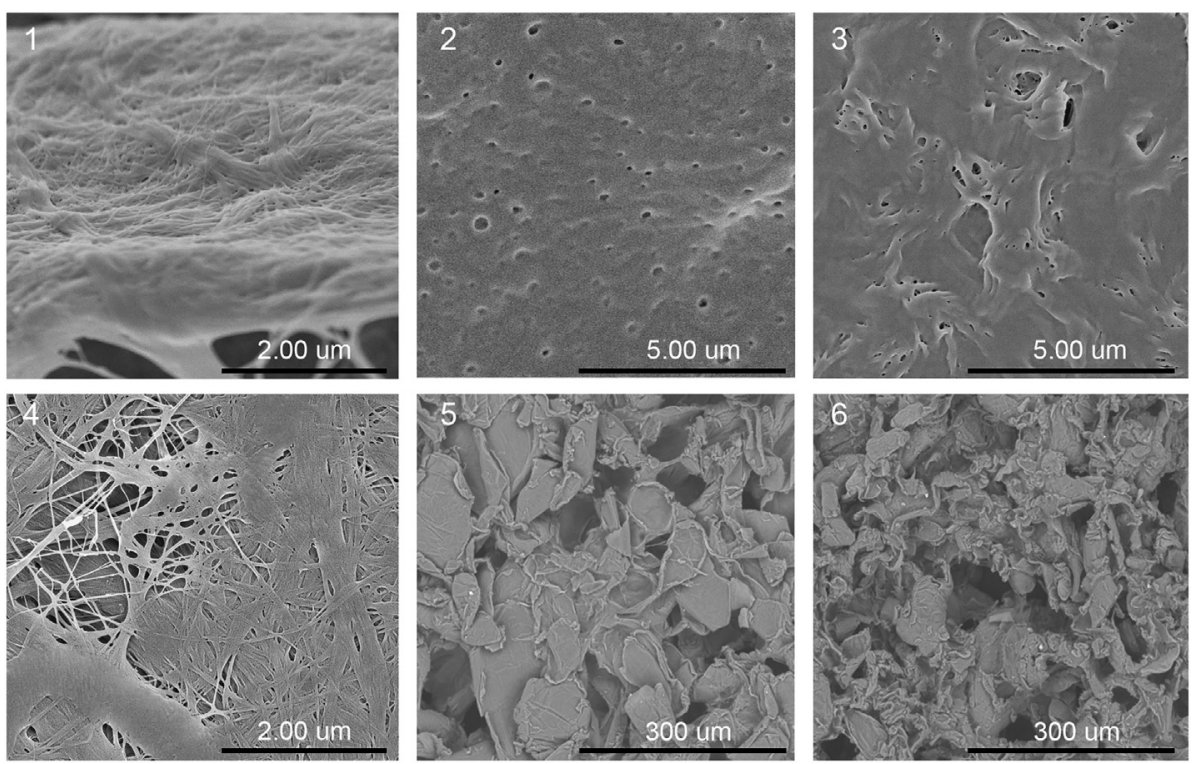

Fig. 2. SEM images of the surface of $\mathrm{BC} / \mathrm{P}(3 \mathrm{HB} / 4 \mathrm{HB})$ composites prepared by different methods (sample indexing is the same as in Fig. 1).

membranes impregnated with PHB-chloroform solutions. The BC nanofibrils involved PHB pellets precipitated inside the BC network. Better tensile properties were observed for composite membranes than for any of the isolated polymers, producing tensile strength and modulus as high as $144 \mathrm{MPa}$ and $15.5 \mathrm{GPa}$, respectively (with 25\% PHB), and elongation of up to $9.5 \%$ (with $75 \%$ PHB), due to good interfacial adhesion and strong interactions between BC and PHB chains. Zhijianga et al. [28] prepared composite films from a $4 \%$ solution of P3HB with poly-3-hydroxyhexanoate, 3-hydroxyoctanoate, and 3hydroxydecanoate tetrapolymer (95:5) with BC powder that showed Young's modulus of between 3000 and $3080 \mathrm{MPa}$, depending on BC concentration in the films (1, 2, and $5 \mathrm{wt} \%)$. The neat P3HB film had Young's modulus of $3160 \mathrm{MPa}$. By contrast, the tensile strength increased with the addition of PHA and BC at lower concentrations, from 26.7 to $22.9 \mathrm{MPa}$. Thus, physical/mechanical properties of composite scaffolds based on PHA and BC are superior to the properties of neat PHA films, and they are largely determined by the methods of production of the composite and the properties of the PHA used.

$\mathrm{BC}$ film is rather hydrophilic, with water contact angle of $45.5 \pm$ $17.6^{\circ}$, while water contact angle of $\mathrm{P}(3 \mathrm{HB} / 4 \mathrm{HB})$ film is $66.5 \pm 4.4$ (Table 2).

Soaking of the $\mathrm{BC}$ film in a $2 \% \mathrm{P}(3 \mathrm{HB} / 4 \mathrm{HB})$ solution produced an insignificant effect on the surface properties of $\mathrm{BC}$. Composites prepared by mixing the $\mathrm{P}(3 \mathrm{HB} / 4 \mathrm{HB})$ solution and $\mathrm{BC}$ powder at ratios of $2: 1$ and $1: 1$ had water contact angles of $43.9 \pm 17.55$ and $36.1 \pm 0.66^{\circ}$, respectively; the dispersive and polar components were larger than those of pure BC, suggesting higher hydrophilicity of the surface of composites. The reason for the high values of water contact angle of the $\mathrm{BC} / \mathrm{P}$ (3HB/4HB) nonwoven membrane composites, $65.3 \pm 2.72^{\circ}$, was that the nonwoven membranes used to grow cellulose were initially dense, with the water contact angle of about $60.5 \pm 4.4^{\circ}$. After drying, the films impregnated with a $5 \% \mathrm{P}(3 \mathrm{HB} / 4 \mathrm{HB})$ solution had a very rough surface and a non-uniform coating, making it impossible to examine their surface properties.

A similar though less pronounced decrease in the surface hydrophobicity of $\mathrm{P} 3 \mathrm{HB} / \mathrm{BC}$ composites was noted by Chiulan et al. [30]. Incorporating $\mathrm{BC}$, which is a hydrophilic material, led to a decrease of the contact angle with 3 for the dried PHB + tetrapolymer/BC (72.3 \pm 6 3.9) sample as compared with PHB-A matrix (77.4 \pm 62.4 ). With CA content increasing in the blend nanofiber scaffold, the contact angle tended to decrease and the scaffold surface was gradually transformed from hydrophobicity to hydrophilicity [31]. When the CA content was $40 \%$, the PHB/CA blend nanofiber scaffold was quite hydrophilic with contact angle of $60 \pm 1.25^{\circ}$.

An important parameter of wound dressings is water vapor transmission rate - a measure of the passage of water vapor through the material. The experimental composites showed different water vapor transmission rates: for the $\mathrm{P}(3 \mathrm{HB} / 4 \mathrm{HB})+\mathrm{BC}$ powder $(2: 1)$, it was the highest ( $5014 \pm 20 \mathrm{~g} / \mathrm{m}^{2} / \mathrm{d}$ ), while for the $\mathrm{P}(3 \mathrm{HB} / 4 \mathrm{HB}$ ) film, it was the lowest $\left(404 \pm 9.1 \mathrm{~g} / \mathrm{m}^{2} / \mathrm{d}\right)$. It is important to increase this parameter to control the buildup of fluid underneath the dressing, make it more breathable, and prevent the establishment of conditions favorable for the development of pathogenic microorganisms.

Thus, in vitro and in vivo experiments were performed using $\mathrm{BC} / \mathrm{P}$ (3HB/4HB) composite films prepared by method 4 (powdered cellulose (particle size of $120 \mu \mathrm{m}$ ) was added to a $3 \% \mathrm{P}(3 \mathrm{HB} / 4 \mathrm{HB})$ solution in chloroform and mixed ultrasonically to homogeneity; then, films were produced by the solvent evaporation technique, at polymer to cellulose ratios of 2:1). These composites were superior to BC films in their physical/mechanical properties; they had hydrophilic surface, adsorption

Table 1

Physical/mechanical properties of the $\mathrm{BC} / \mathrm{P}(3 \mathrm{HB} / 4 \mathrm{HB})$ hybrids.

\begin{tabular}{|c|c|c|c|}
\hline Sample & Young's modulus, MPa & Fracture strength, MPa & Fracture strain,\% \\
\hline Initial $\mathrm{P}(3 \mathrm{HB} / 4 \mathrm{HB})$ & $1112.34 \pm 23.3$ & $5.33 \pm 1.02$ & $10.70 \pm 6.32$ \\
\hline Initial BC & $47.60 \pm 6.32$ & $0.11 \pm 0.13$ & $4.35 \pm 0.82$ \\
\hline Nonwoven membranes & $113.54 \pm 9.85$ & $9.30 \pm 1.24$ & $180.33 \pm 20.71$ \\
\hline $\mathrm{BC}+$ nonwoven membranes & $272.3 \pm 27.2$ & $8.67 \pm 0.86$ & $3.65 \pm 0.4$ \\
\hline $\mathrm{P}(3 \mathrm{HB} / 4 \mathrm{HB})+\mathrm{BC}$ powder $(2: 1)$ & $65.08 \pm 7.1$ & $0.88 \pm 0.08$ & $3.45 \pm 0.34$ \\
\hline $\mathrm{P}(3 \mathrm{HB} / 4 \mathrm{HB})+\mathrm{BC}$ powder $(1: 1)$ & $63.41 \pm 5.6$ & $0.83 \pm 0.07$ & $3.47 \pm 0.57$ \\
\hline $\mathrm{BC}+2 \% \mathrm{P}(3 \mathrm{HB} / 4 \mathrm{HB})$ solution & $115.99 \pm 10.9$ & $6.65 \pm 1.2$ & $6.25 \pm 0.94$ \\
\hline $\mathrm{BC}$ (moisture content $95-97 \%)+2 \% \mathrm{P}(3 \mathrm{HB} / 4 \mathrm{HB})$ solution & $146.76 \pm 14.6$ & $5.63 \pm 0.82$ & $5.71 \pm 1.3$ \\
\hline
\end{tabular}


Table 2

Surface properties of $\mathrm{BC} / \mathrm{P}(3 \mathrm{HB} / 4 \mathrm{HB})$ hybrids.

\begin{tabular}{|c|c|c|c|c|}
\hline Sample & Water contact angle, degrees & Dispersive component, mN/m & Polar component, $\mathrm{mN} / \mathrm{m}$ & Water vapor transmission rate, $\mathrm{g} / \mathrm{m}^{2} / \mathrm{d}$ \\
\hline Initial BC & $45.5 \pm 17.6$ & $28 \pm 9.24$ & $17.5 \pm 8.37$ & $2655 \pm 21$ \\
\hline $\mathrm{P}(3 \mathrm{HB} / 4 \mathrm{HB})$ film & $66.5 \pm 4.4$ & $22.90 \pm 17.6$ & $42.2 \pm 17.6$ & $404 \pm 9.1$ \\
\hline $\mathrm{P}(3 \mathrm{HB} / 4 \mathrm{HB})$ nonwoven membrane & $60.5 \pm 4.4$ & $22.40 \pm 15.0$ & $12.2 \pm 10.5$ & $1000 \pm 7$ \\
\hline $\mathrm{BC}+2 \% \mathrm{P}(3 \mathrm{HB} / 4 \mathrm{HB})$ solution & $46.2 \pm 13.77$ & $45.2 \pm 11.74$ & $21 \pm 2.03$ & $4473 \pm 10$ \\
\hline $\mathrm{P}(3 \mathrm{HB} / 4 \mathrm{HB})+\mathrm{BC}$ powder $(2: 1)$ & $43.9 \pm 17.55$ & $22 \pm 9.39$ & $21.9 \pm 8.17$ & $5014 \pm 20$ \\
\hline $\mathrm{P}(3 \mathrm{HB} / 4 \mathrm{HB})+\mathrm{BC}$ powder $(1: 1)$ & $36.1 \pm 0.66$ & $35.5 \pm 0.58$ & $29.6 \pm 0.08$ & $1732 \pm 9$ \\
\hline $\mathrm{BC}+$ nonwoven membrane & $65.3 \pm 2.72$ & $45.6 \pm 1.29$ & $19.7 \pm 1.42$ & $2005 \pm 15$ \\
\hline
\end{tabular}

properties, and microstructure suitable for cell culture, which was confirmed by electron microscopy.

\subsection{Biological properties of $B C / P(3 H B / 4 H B)$ hybrids}

Biological compatibility of $\mathrm{BC} / \mathrm{P}(3 \mathrm{HB} / 4 \mathrm{HB})$ composites was studied in fibroblast culture. MTT assay showed that the best scaffolds for fibroblast growth were the films prepared by the solvent evaporation technique at a polymer: cellulose ratio of 2:1 (Fig. 3).

The ability of $\mathrm{P}(3 \mathrm{HB}) / \mathrm{BC}$ composites to facilitate growth and proliferation of ATDC5 cells was described in a study by Zhijiang et al. [31]. Nonwoven PHB/CA composites favored cell proliferation more effectively than PHB after $72 \mathrm{~h}$ of cultivation. In a study by Akaraonye et al. [29], the P(3HB)/MFC 3D composite scaffold with 40 wt\% MFC content showed a slightly lower cell proliferation at day 4 (97\%) compared to the neat $\mathrm{P}(3 \mathrm{HB})$ scaffold samples (108\%). At day 7, however, it was found that the cell proliferation on the $40 \mathrm{wt} \%$ MFC content composite was higher $(117 \%)$ than that observed on the neat $\mathrm{P}(3 \mathrm{HB})$ scaffold (105\%).

In the present study, investigation of physical/mechanical and biological properties of the experimental hybrids showed that the films prepared by casting the solutions of the polymer: cellulose powder mixture (2:1) followed by solvent evaporation were the most attractive candidates to be used as scaffolds for growing fibroblasts. These types of hybrids were loaded with drugs promoting wound healing (actovegin, solcoseryl) and fibroblasts derived from the adipose tissue MSC (Fig. 3). Hybrids loaded with 5.0\% actovegin or solcoseryl were the most favorable for fibroblast growth.

The study of the kinetics of drug (actovegin, solcoseryl) release from the $\mathrm{BC} / \mathrm{P}(3 \mathrm{HB} / 4 \mathrm{HB})$ films to the phosphate-buffered saline showed that the drugs were released at a faster rate from the films containing higher drug concentrations. Although actovegin and solcoseryl are drugs with similar effects, after $72 \mathrm{~h}, 0.47 \mathrm{mg} / \mathrm{mL}$, or $43 \%$, of the drug was released from the films loaded with $5 \%$ actovegin and just $0.11 \mathrm{mg} / \mathrm{mL}$, or $21 \%$, of solcoseryl was released from the films with the same drug

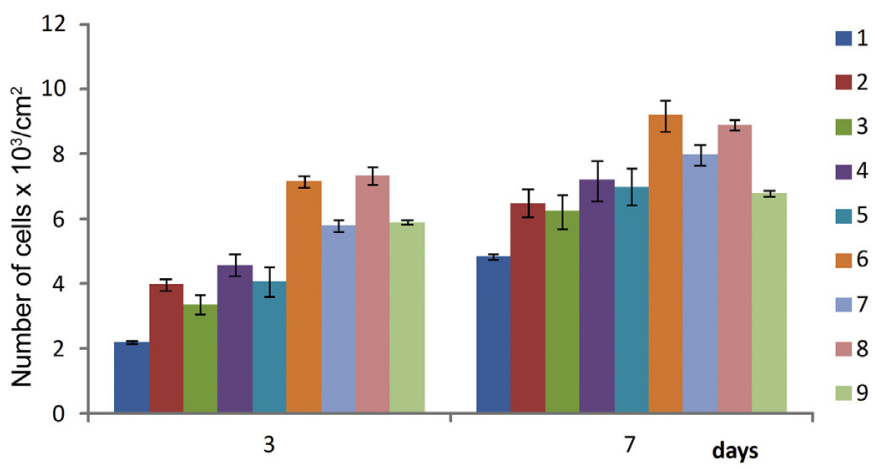

Fig. 3. MTT assay: viable fibroblasts on hybrid $\mathrm{BC} / \mathrm{P}(3 \mathrm{HB} / 4 \mathrm{HB})$ films: 1 - control (polystyrene); $2-\mathrm{BC}+$ nonwoven membrane; $3-\mathrm{BC}+2 \% \mathrm{P}(3 \mathrm{HB} / 4 \mathrm{HB})$ solution; $4-\mathrm{P}$ $(3 \mathrm{HB} / 4 \mathrm{HB})+\mathrm{BC}$ powder $(2: 1) ; 5-\mathrm{P}(3 \mathrm{HB} / 4 \mathrm{HB})+\mathrm{BC}$ powder $(1: 1) ; 6-\mathrm{P}(3 \mathrm{HB} / 4 \mathrm{HB})$ $+\mathrm{BC}$ powder $(2: 1)+$ actovegin $(5.0 \%) ; 7-\mathrm{P}(3 \mathrm{HB} / 4 \mathrm{HB})+\mathrm{BC}$ powder $(2: 1)+$ actovegin $(1.0 \%) ; 8-\mathrm{P}(3 \mathrm{HB} / 4 \mathrm{HB})+\mathrm{BC}$ powder $(2: 1)+\operatorname{solcoseryl}(5.0 \%) ; 9-\mathrm{P}(3 \mathrm{HB} /$ $4 \mathrm{HB})+\mathrm{BC}$ powder $(2: 1)+$ solcoseryl $(1.0 \%)$. concentration. Therefore, films loaded with 5\% actovegin were chosen for further studies (Fig. 4).

\subsection{In vivo experiment}

Models of third-degree skin burns were created on anesthetized rats. The animals were divided into 4 groups, 6 rats in each group. In the control group, the defect was closed with a VaskoPran dressing and covered with a dry sterile gauze bandage. In treatment groups, three types of the experimental wound dressings were used: $\mathrm{BC} / \mathrm{P}$ (3HB/4HB), a BC/P(3HB/4HB)/actovegin and a BC/P(3HB/4HB)/fibroblasts differentiated from MSCs wound dressing.

After surgical intervention, all animals were healthy and active, displayed normal eating behavior, and moved on their own. After the treatment group animals awakened from anesthesia, they did not show any signs of pain. Wound healing process was monitored using the following approaches: planimetric measurements of the wounds and determination of wound surface area reduction and healing rate; histological examination; biochemical and molecular techniques of detecting angiogenesis factor, inflammation, type I collagen, keratin 10 , and keratin 14. Measurements of the wound surface area showed that wound healing occurred at a faster rate in the treatment groups (Figs. 5, 6)

The surface area of the wound closed with the $\mathrm{BC} / \mathrm{P}(3 \mathrm{HB} / 4 \mathrm{HB}) /$ actovegin wound dressing was reduced to $1 \mathrm{~cm}^{2}$ (67\% of the initial area) at Day 3, to 33\% at Day 7, and to 7.3\% at Day 14. A similar healing process was observed in the group with the $\mathrm{BC} / \mathrm{P}(3 \mathrm{HB} / 4 \mathrm{HB}) /$ fibroblasts wound dressings: the wound area was reduced to $69.3 \%$ at Day 3, to $40 \%$ at Day 7 , and to $9 \%$ at Day 14 . The heling rates in these groups were similar too, about $0.4 \mathrm{~cm}^{2} / \mathrm{d}$. In the group with the wounds closed with the $\mathrm{BC} / \mathrm{P}(3 \mathrm{HB} / 4 \mathrm{HB})$ films containing no cells or actovegin, the healing rate was somewhat slower, with the wound area reduced to about $12 \%$ of the initial area by the end of the experiment. In the control group, a much poorer result was obtained: at Day 14, the wound area was

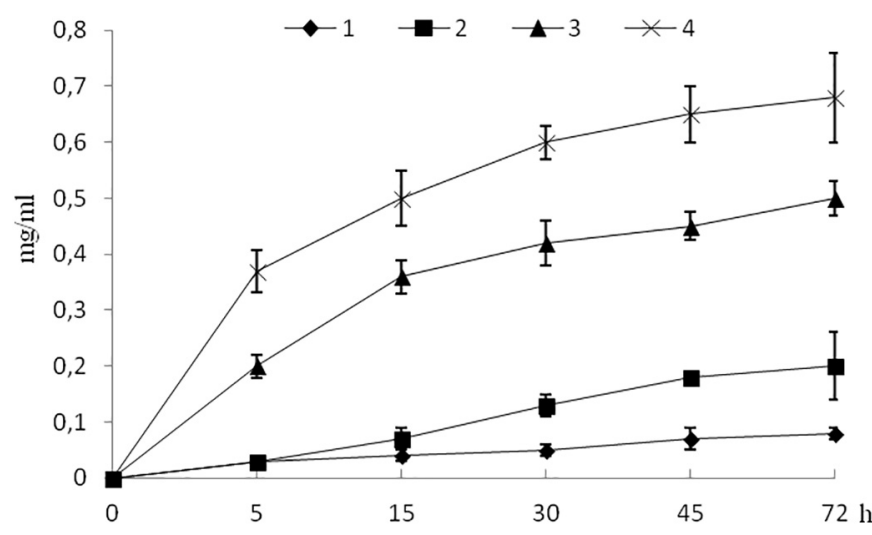

Fig. 4. The drug release (actovegin, solcoseryl) from the $\mathrm{BC} / \mathrm{P}(3 \mathrm{HB} / 4 \mathrm{HB})$ films: $1-\mathrm{P}(3 \mathrm{HB} /$ $4 \mathrm{HB})+\mathrm{BC}$ powder $(2: 1)+$ solcoseryl $(1.0 \%), 2-\mathrm{P}(3 \mathrm{HB} / 4 \mathrm{HB})+\mathrm{BC}$ powder $(2: 1)+$ actovegin $(1.0 \%) ; 3-\mathrm{P}(3 \mathrm{HB} / 4 \mathrm{HB})+\mathrm{BC}$ powder $(2: 1)+\operatorname{solcoseryl}(5.0 \%) ; 4-\mathrm{P}(3 \mathrm{HB} /$ $4 \mathrm{HB})+\mathrm{BC}$ powder $(2: 1)+$ actovegin $(5.0 \%)$ 


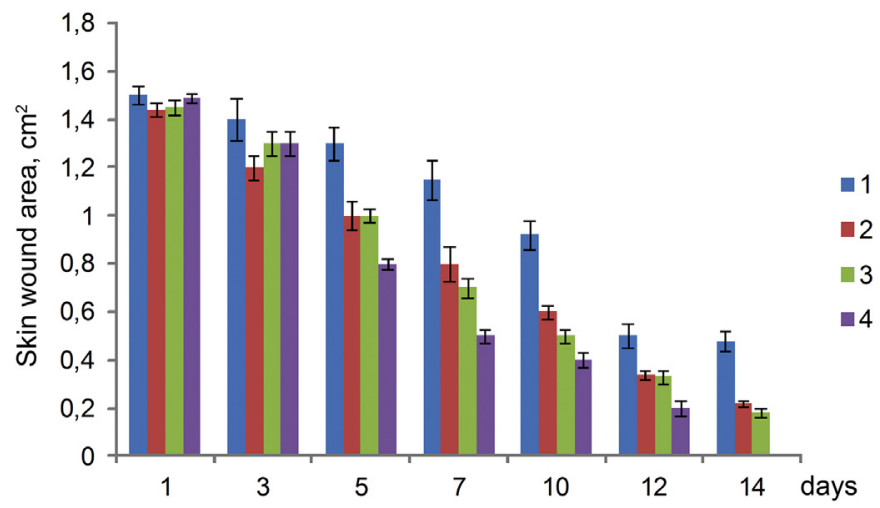

Fig. 5. Dynamics of reduction in the skin wound area in the groups of animals with different wound dressings: 1 - VoskoPran (control), 2 - BC/P(3HB/4HB); 3 - BC/P(3HB/ $4 \mathrm{HB})$ /actovegin; 4 - BC/P(3HB/4HB)/fibroblasts.

reduced to $30.6 \%$ of its initial area, and the average healing rate was $0.19 \mathrm{~cm}^{2} / \mathrm{d}$.

Histological examination showed that at Day 3, the necrotic zones in all groups were characterized by considerable destructive changes of the epidermis, dermis, and subcutaneous tissue, with the total necrosis of skin appendages (Fig. 7). The surface of the wound was uneven and covered by a layer of necrotic masses with residual epidermis. Under the necrotic zone, in the layer adjacent to the undamaged tissue, there was an edema pronounced to different extents, and infiltration dominated by band neutrophils. In the control group, the thickness of epithelial injury (scab) was $28.45 \pm 8.3 \mu \mathrm{m}$, and the number of band neutrophils reached $10 \pm 2$ cells (in 10 fields of view). In the BC/P (3HB/4HB) group, the scab was $20.29 \pm 2.3$ - $\mu \mathrm{m}$ thick, and the number of band neutrophils was $6 \pm 2$ cells (in 10 fields of view). In the BC/P (3HB/4HB)/actovegin and $\mathrm{BC} / \mathrm{P}(3 \mathrm{HB} / 4 \mathrm{HB}) /$ fibroblasts groups, the thickness of the scab was $18.1 \pm 1 \mu \mathrm{m}$, and the number of band neutrophils was $6 \pm 2$ cells (in 10 fields of view). In the center of the burn, there were no hair follicles and sebaceous glands or they showed pronounced necrotic changes. There were no signs of regeneration in the center and at the edges of the wounds.

At Day 14, in all groups, the thickness of the layer of necrotic masses covering the wound was reduced (Fig. 8). In all treatment groups, the wound bed was represented by fibrous connective tissue with nonuniformly distributed infiltration by lymphocytes, macrophages, and segmented leukocytes. Rapid proliferation of fibroblasts was observed at the wound edges beneath the epidermis. It was accompanied by the development of relatively few small blood vessels. In groups with membranes loaded with actovegin and fibroblasts, either there was no leukocyte infiltration in the wound or it was represented by the minimal number of segmented leukocytes ( $2 \pm 1$ cells in 10 fields of view). In the control group, leukocyte infiltration on the wound bed, in the layer adjacent to viable tissues, was still observed, but it was weaker than in the previous phases of the experiment. Rapid epidermization was observed in all groups, but in the treatment groups, it was more effective, especially in the groups with membranes loaded with agents promoting wound healing (actovegin, fibroblasts). In those groups, the wounds were almost completely covered with a layer of epidermis (Fig. 8).
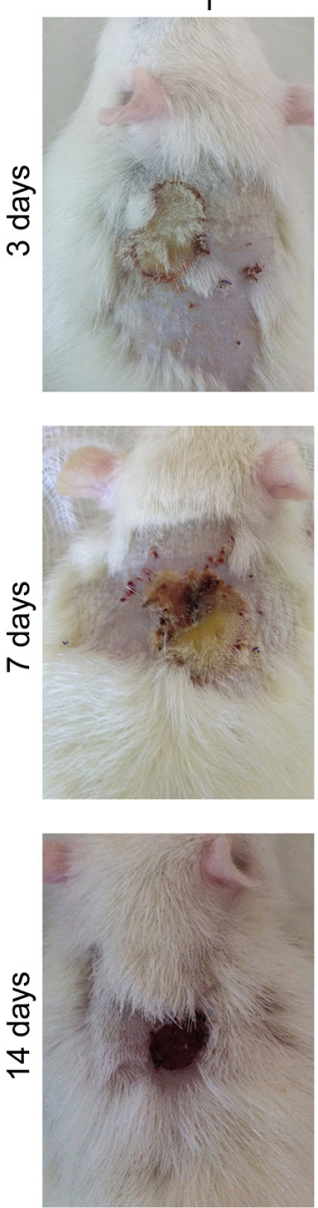
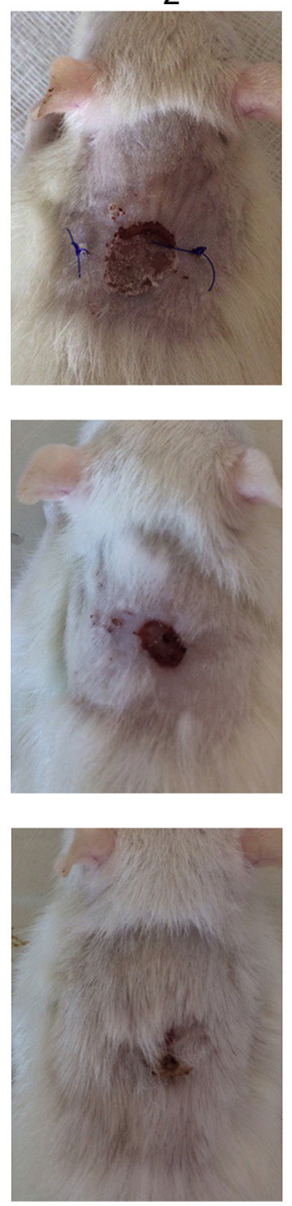
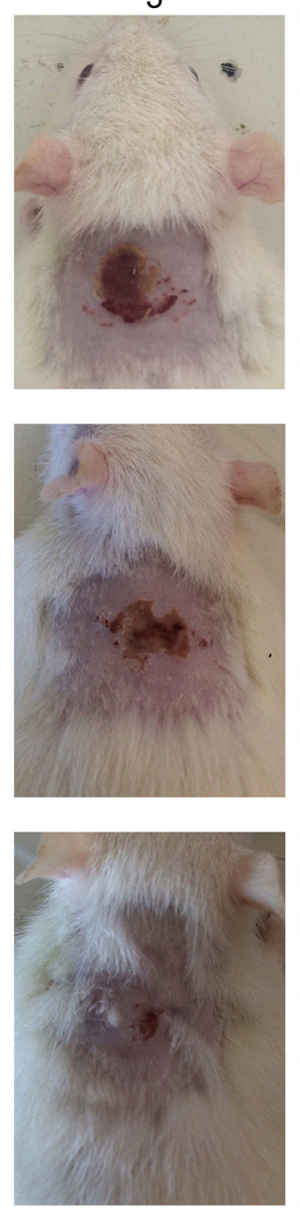

4
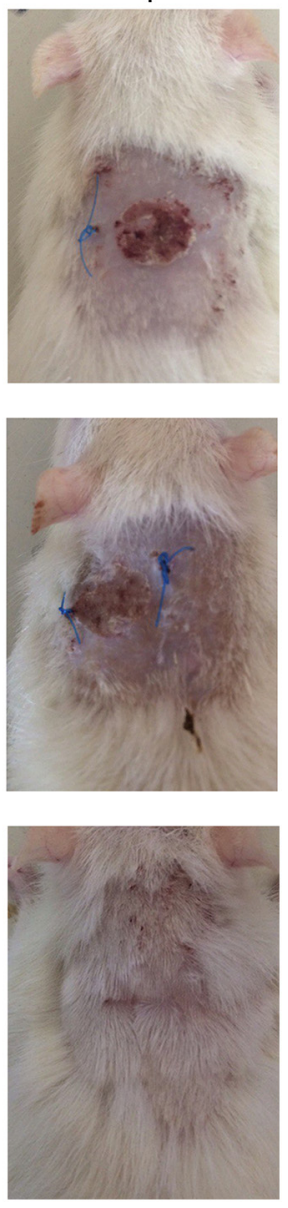

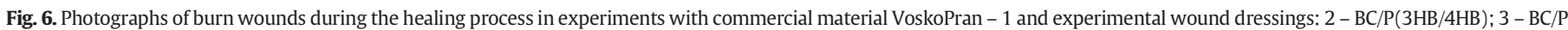
(3HB/4HB)/actovegin; 4 - BC/P(3HB/4HB)/fibroblasts; Days 3, 7, and 14 of the experiment. 

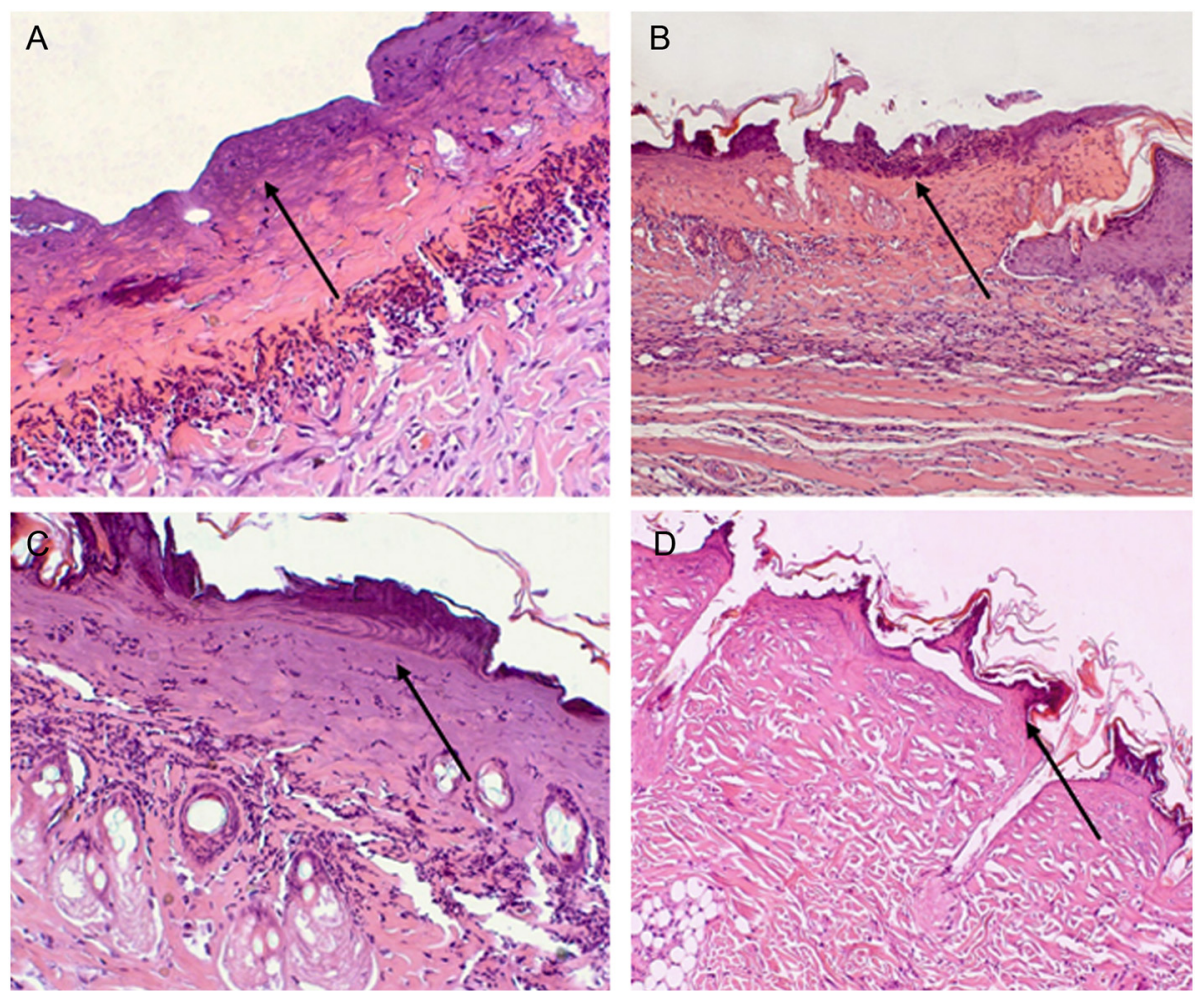

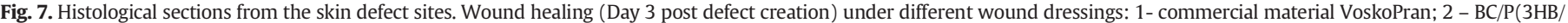
$4 \mathrm{HB}) ; 3$ - the $\mathrm{BC} / \mathrm{P}(3 \mathrm{HB} / 4 \mathrm{HB}) /$ actovegin hybrid membrane; 4 - the $\mathrm{BC} / \mathrm{P}(3 \mathrm{HB} / 4 \mathrm{HB}) /$ fibroblasts hybrid membrane. Hematoxylin and eosin staining, $100 \times$.

The thin new epidermis grew under the layer of necrotic masses (scab) covering the wound. In the marginal layer, epidermis formed thin acantotic strands, which would later develop into hair follicles. No granulation tissue was formed during epidermization. The underlying dermis contained few moderately plethoric arteries and enlarged veins with a large number of erythrocytes. The inflammatory infiltration outside the wound consisted of mononuclear cells; it was moderate and did not spread beyond the dermis. In the control group,
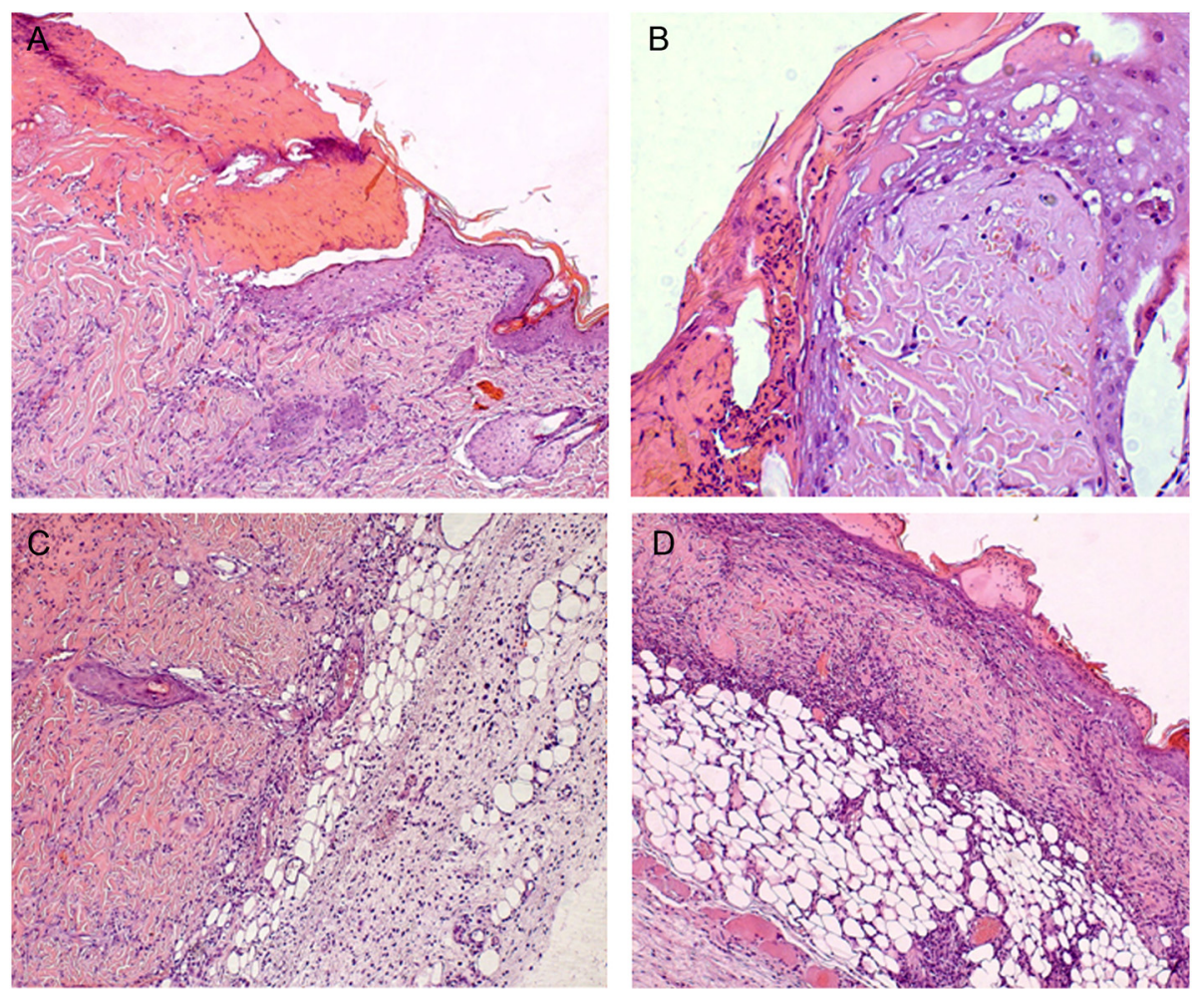

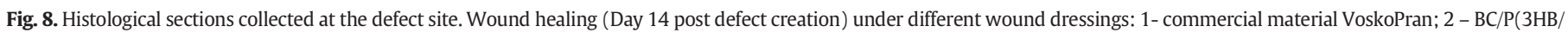
$4 \mathrm{HB}) ; 3$ - the $\mathrm{BC} / \mathrm{P}(3 \mathrm{HB} / 4 \mathrm{HB}) /$ actovegin hybrid membrane; 4 - the $\mathrm{BC} / \mathrm{P}(3 \mathrm{HB} / 4 \mathrm{HB}) /$ fibroblasts hybrid membrane. Hematoxylin and eosin staining, $100 \times$. 

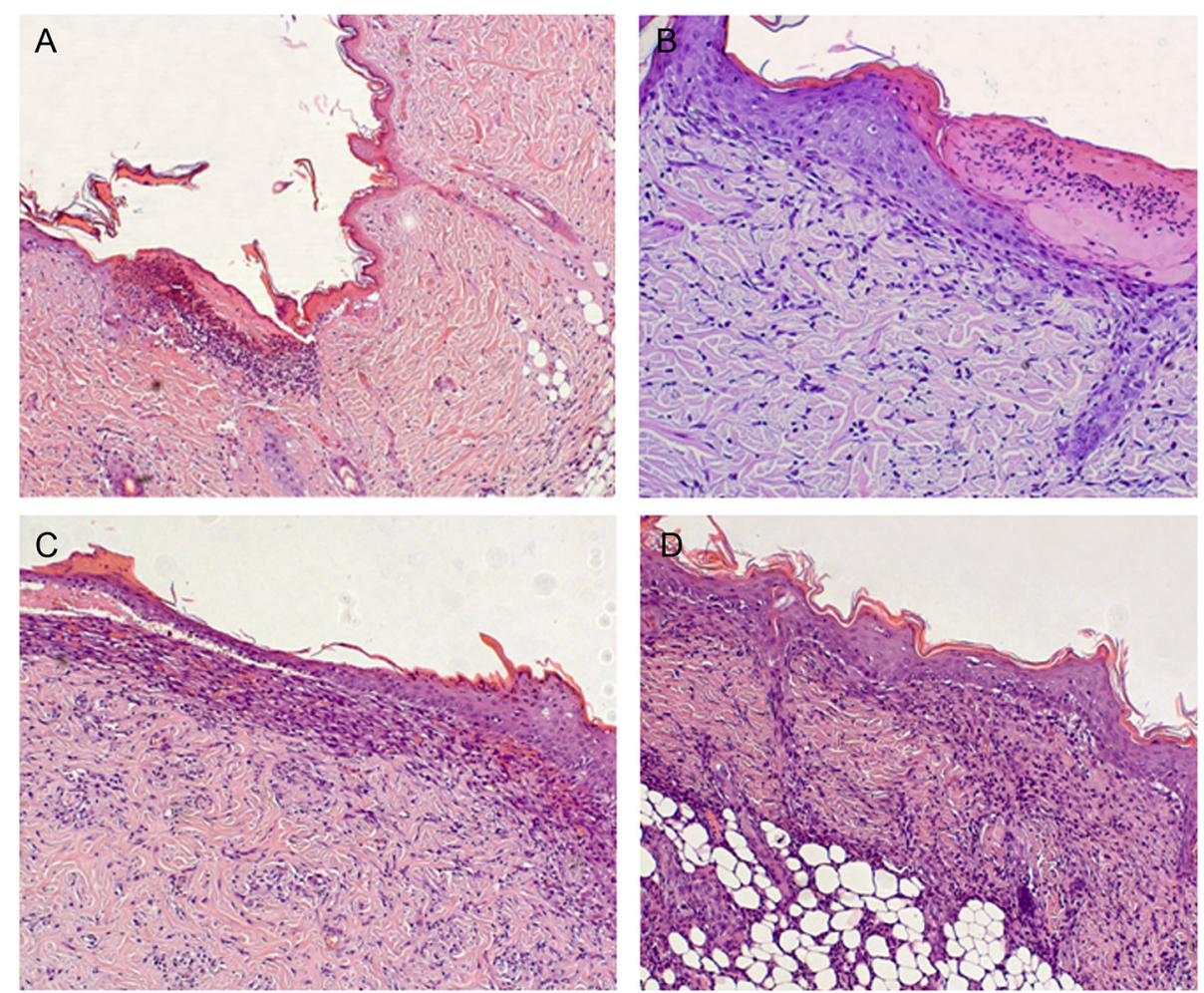

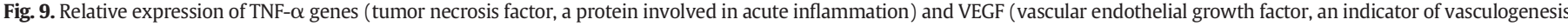

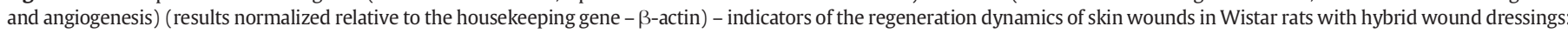
1 - BC/P(3HB/4HB); 2 - BC/P(3HB/4HB)/fibroblasts; 3 - BC/P(3HB/4HB)/actovegin; 4 - VoskoPran (control).

the necrotic zone was surrounded by a more pronounced leukocyte bank, which penetrated to the underlying subcutaneous tissue in places. Similar, though weaker, changes were observed in the animals with the $\mathrm{BC} / \mathrm{P}(3 \mathrm{HB} / 4 \mathrm{HB})$ wound dressings.

To study the mechanism of the healing process, real-time PCR was performed to determine the factors characterizing the degree of inflammation, vascularization, and formation of the new connective tissue at the defect site. Relative expression of VEGF (vascular endothelial growth factor, an indicator of vasculogenesis and angiogenesis) was higher in the groups with hybrid membranes loaded with fibroblasts or actovegin (Fig. 9). In the $\mathrm{BC} / \mathrm{P}(3 \mathrm{HB} / 4 \mathrm{HB}) /$ actovegin group, $\Delta \mathrm{Ct}$ was $20 \%$ higher than in the VoskoPran group and 30\% higher than in the $\mathrm{BC} / \mathrm{P}(3 \mathrm{HB} / 4 \mathrm{HB})$ group. In the group with the membranes loaded with fibroblasts, relative expression was 5-6\% lower but it was also higher than in the control group.

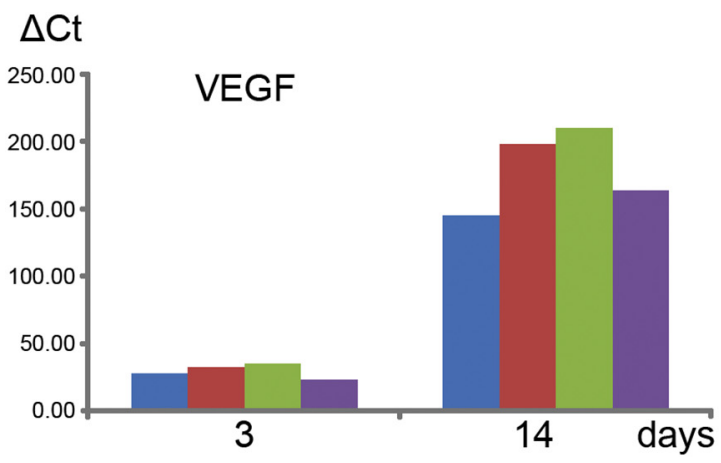

Relative TNF- $\alpha$ (tumor necrosis factor, a protein involved in acute inflammation) gene expression decreased considerably by the end of the experiment (Fig. 10), and in the groups with membranes loaded with fibroblasts and actovegin, it was lower by a factor of two than in the $\mathrm{BC} / \mathrm{P}(3 \mathrm{HB} / 4 \mathrm{HB})$ and VoskoPran groups, suggesting alleviation of inflammation. The PCR method was used to determine expression of type I collagen (Col-1) (a signal of connective tissue formation), keratin 10 (K10) and keratin 14 (K14) (signals of formation of the spinous and granular layers in the epidermis during tissue regeneration) genes. The number of Col-1, K10, and K14 cDNA copies was higher than that in the control by a factor of $1.5-2.0$, also suggesting more effective wound healing beneath the experimental hybrid wound dressings.

The results of experiments in which the BC-based composites were tested as wound dressings are consistent with the literature data suggesting BC effectiveness in healing skin wounds. However, other studies

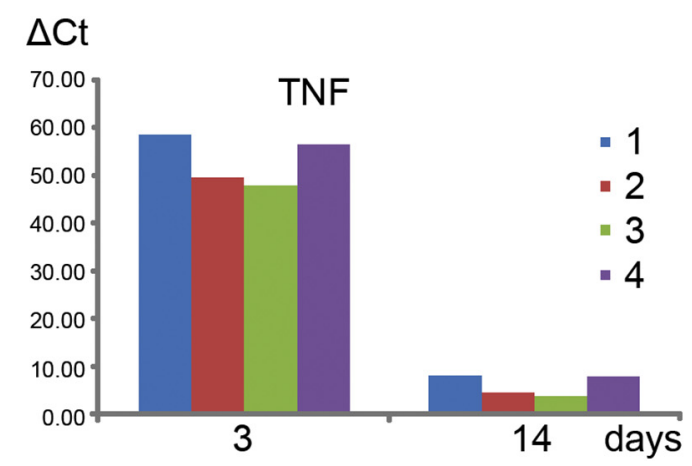

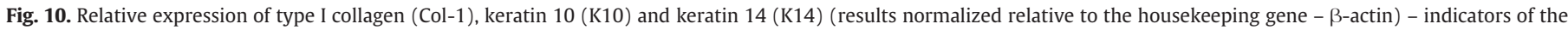

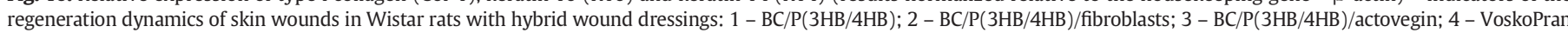
(control). 


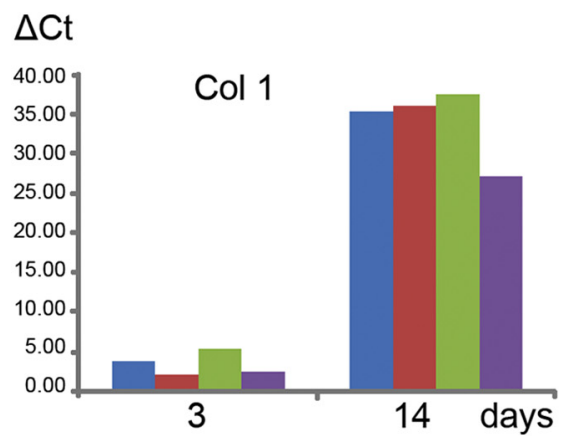

$\Delta \mathrm{Ct}$

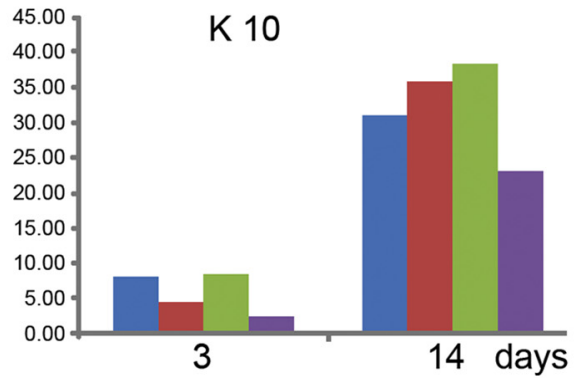

$\Delta \mathrm{Ct}$

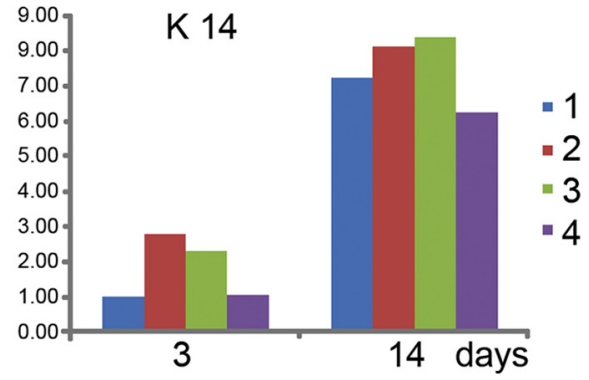

Fig. 11.

described using BC in combination with the materials other than PHAs. Bajpai et al. [10] demonstrated $97.2 \%$ healing of full-thickness skin wounds in Albino Wistar rats under a film of BC nanocrystals/chitosan incorporating silver and curcumin particles. Potential use of $\mathrm{BC}$ modified with carboxymethyl groups and loaded with chitosan particles with encapsulated curcumin as material for healing skin wounds was shown in a study by Rojewska et al. [11]. Gelatin/BC scaffolds accelerated healing of skin wounds in mice [12]; BC composites with silk fibroin effectively healed model skin wounds in rats [13], and that was confirmed by measuring the levels of expression of wound healing markers. Singla et al. [14] used hydrogels prepared from bamboo cellulose nanocrystals loaded with silver particles to heal skin wounds in streptozotocin induced diabetic mice. Wounds were $98-100 \%$ recovered within 18 days as confirmed by detecting molecular markers of tissue genesis and a significant increase in the expression of collagen and growth factors (FCF, PDGF, and VEGF), which caused enhanced re-epithelization, vasculogenesis, and collagen deposition (Fig. 11).

In a study by Kwak et al. [5], the second-degree $1 \mathrm{~cm}^{2}$ burn injury in a rat model was closed with a bacterial cellulose membrane. The expression of VEGF and angiopoietin-1 (Ang-1) was considerably decreased at Days 10 and 15. Moreover, the level of collagen expression was much higher in the $\mathrm{BC}$ group than in the group of rats with the wounds closed with gauze. Although the topical application of bacterial cellulose membranes for two weeks accelerated wound healing, including tissue regeneration, connective formation, and angiogenesis, no complete skin healing occurred. In a study by Lin et al. [2], membranes based on bacterial cellulose and chitosan and on cellulose alone were used to close 1.2$\mathrm{cm} \times 1.2$-cm degloving wounds in rats. The wounds were 90 and $88 \%$ healed under the composite material and cellulose, respectively, after 21 days of the experiment. The authors concluded that skin regeneration should be accelerated by adding agents promoting wound healing (drugs or cells).

\section{Conclusion}

Thus, results obtained in this study suggest that biotechnological wound dressings based on bacterial cellulose and $\mathrm{P}(3 \mathrm{HB} / 4 \mathrm{HB})$ in combination with wound healing drugs and cells are effective in managing skin wounds.

\section{Acknowledgements}

The authors would like to thank Ivan Nemtsev (Federal Research Center Krasnoyarsk Scientific Center of the Siberian Branch of the RAS) for their support with SEM.

\section{Conflict of interest}

The authors disclose that no conflicting interests associated with the manuscript exist.

\section{References}

[1] A.A. Artyukhov, M.I. Shtilman, A.N. Kuskov, A.P. Fomina, D.E. Lisovyy, A.S. Golunova, A.M. Tsatsakis, Macroporous polymeric hydrogels formed from acrylate modified polyvinyl alcohol macromers, J. Polym. Res. 18 (2011) 667-673https://link. springer.com/article/10.1007/s10965-010-9462-9.

[2] A.A. Artyukhov, M.I. Shtilman, A.N. Kuskov, L.I. Pashkova, A.M. Tsatsakis, A.K. Rizosc, Polyvinyl alcohol cross-linked macroporous polymeric hydrogels:structure formation and regularity investigation, J. Non-Cryst. Solids 357 (2011) 700-706, https:// doi.org/10.1016/j.jnoncrysol.2010.06.038.

[3] F. Khan, M. Tanaka, Designing smart biomaterials for tissue engineering, Int. J. Mol. Sci. 19 (2018) 1-17, https://doi.org/10.3390/ijms19010017.

[4] W.C. Lin, C.C. Lien, H.J. Yeh, C.M. Yu, S. Hsu, Bacterial cellulose and bacterial cellulose-chitosan membranes for wound dressing applications, Carbohydr. Polym. 94 (2013) 603-611, https://doi.org/10.1016/j.carbpol.2013.01.076.

[5] M.H. Kwak, J.E. Kim, J. Go, E.K. Koh, S.H. Song, H.J. Son, H.S. Kim, Y.H. Yun, Y.J. Jung, D.Y. Hwang, Bacterial cellulose membrane produced by Acetobacter sp. A10 for burn wound dressing application, Carbohydr. Polym. 122 (2015) 387-398, https://doi. org/10.1016/j.carbpol.2014.10.049.

[6] W.S. Chang, H.H. Chen, Physical properties of bacterial cellulose composites for wound dressings, Food Hydrocoll. 53 (2016) 75-83, https://doi.org/10.1016/j. foodhyd.2014.12.009.

[7] W. Shao, H. Liu, X. Liu, S. Wang, J. Wu, R. Zhang, H. Min, M. Huang, Development of silver sulfadiazine loaded bacterial cellulose/sodium alginate composite films with enhanced antibacterial property, Carbohydr. Polym. 132 (2015) 351-358, https:// doi.org/10.1016/j.carbpol.2015.06.057.

[8] S. Kirdponpattara, A. Khamkeaw, N. Sanchavanakit, P. Pavasant, M. Phisalaphong, Structural modification and characterization of bacterial cellulose-alginate composite scaffolds for tissue engineering, Carbohydr. Polym. 132 (2015) 146-155, https:// doi.org/10.1016/j.carbpol.2015.06.059.

[9] P. Brassolatti, H.W. Kido, P.S. Bossini, P.R. Gabbai-Armelin, A.N. Otterço, L. AlmeidaLopes, L.M. Zanardi, M.A. Napolitano, L.R.D.S. de Avó, L.A. Forato, F.M. AraújoMoreira, N.A. Parizotto, Bacterial cellulose membrane used as biological dressings on third-degree burns in rats, Biomed. Mater. Eng. 29 (2018) 29-42, https://doi. org/10.3233/BME-171710.

[10] S.K. Bajpai, N. Chand, S. Ahuja, Investigation of curcumin release from chitosan/cellulose micro crystals (CMC) antimicrobial films, Int. J. Biol. Macromol. 79 (2015) 440-448, https://doi.org/10.1016/j.ijbiomac.2015.05.012.

[11] A. Rojewska, A. Karewicz, K. Boczkaja, K. Wolski, M. Kępczyński, S. Zapotoczny, M. Nowakowska, Modified bionanocellulose for bioactive wound-healing dressing, Eur. Polym. J. 96 (2017) 200-209, https://doi.org/10.1016/j.eurpolymj.2017.09.010.

[12] S.F. Goma, T.M. Madkour, S. Moghannem, I.M. El-Sherbinyb, New polylactic acid/ cellulose acetate-based antimicrobial interactive single dose nanofibrous wound dressing mats, Int. J. Biol. Macromol. 105 (2017) 1148-1160, https://doi.org/10. 1016/j.ijbiomac.2017.07.145.

[13] A.A. Shefa, J. Amirian, H.J. Kang, S.H. Bae, H. Jung, H.J. Choi, S.Y. Lee, B.T. Lee, In vitro and in vivo evaluation of effectiveness of a novel TEMPO-oxidized cellulose nanofiber-silk fibroin scaffold in wound healing, Carbohydr. Polym. 177 (2017) 284-296, https://doi.org/10.1016/j.carbpol.2017.08.130.

[14] R. Singla, S. Soni, V. Patial, P.M. Kulurkar, A. Kumari, Y.S. Padwad, S.K. Yadav, Cytocompatible anti-microbial dressings of syzygiumcumini cellulose nanocrystals decorated with silver nanoparticles accelerate acute and diabetic wound healing, Sci. Rep. 7 (2017) 1-13, https://doi.org/10.1038/s41598-017-08897-9.

[15] N. Mohamad, E.Y.X. Loh, M.B. Fauzi, M.H. Ng, M.C.I. Mohd Amin, In vivo evaluation of bacterial cellulose/acrylic acid wound dressing hydrogel containing keratinocytes and fibroblasts for burn wounds, Drug Deliv. Transl. Res. 8 (2018) 1-9, https://doi. org/10.1007/s13346-017-0475-3.

[16] E.Y.X. Loh, N. Mohamad, Mh.B. Fauzi, M.H. Ng, S.F. Ng, M.C.I.M. Amin, Development of a bacterial cellulose-based hydrogel cell carrier containing keratinocytes and fibroblasts for full-thickness wound healing, Sci. Rep. 8 (2018) 1-9, https://doi.org/ 10.1038/s41598-018-21174-7.

[17] E.I. Shishatskaya, T.G. Volova, A.P. Puzyr, O.A. Mogilnaya, S.N. Efremov, Tissue response to the implantation of biodegradable polyhydroxyalkanoate sutures, J. Mater. Sci. Mater. Med. 15 (2004) 719-728, https://doi.org/10.1023/B:JMSM. 0000030215.49991.0d 
[18] A.V. Protopopov, T.A. Kochkina, E.P. Konstantinov, E.I. Shishatskaia, S.N Efremov, T.G. Volova, I.I. Gitelson, Investigations of application of PHA coating to enhance biocompatibility of vascular stents, Dokl. Biol. Sci. 401 (2005) 85-87.

[19] E.I. Shishatskaya, E.D. Nikolaeva, O.N. Vinogradova, T.G. Volova, Experimental wound dressings of degradable PHA for skin defect repair, J. Mater. Sci. Mater. Med. 27 (2016) 1-16, https://doi.org/10.1007/s10856-016-5776-4.

[20] A.A. Shumilova, M.P. Myltygashev, A.K. Kirichenko, E.D. Nikolaeva, T.G. Volova, E.I. Shishatskaya, Porous 3D implants of degradable poly-3-hydroxybutyrate used to enhance regeneration of rat cranial defect, J. Biomed. Mater. Res. A 105 (2017) 566-577, https://doi.org/10.1002/jbm.a.35933.

[21] A.B. Protopopov, E.P. Konstantinov, E.I. Shishatskaya, S.N. Efremov, T.G. Volova, I.I. Gitelson, The use of resorbable polyesters to increase the biocompatibility of intravascular stents, Technol. of liv. syst. 2 (2008) 25-33.

[22] M.P. Myttygashev, A.N. Boyandin, A.A. Shumilova, F.P. Kapsargin, E.I. Shishatskaya, A.K. Kirichenko, TG Volova Study of the Effectiveness of the Use of Biodegradable Stents on the Basis of Polyhydroxyalkanoates in the Plasty of the Pyeloureteral Segment Urology, vol. 1, 2017 16-22.

[23] N.M. Markelova, E.I. Shishatskaya, Y.S. Vinnik, D.V. Cherdantsev, I.I. Beletskiy, M.N. Kuznetsov, L.D. Zykova, In vitro justification of using endobiliary stents made of polyhydroxyalkanoates, Macromol. Symp. 269 (2008) 82-91, https://doi.org/10. 1002/masy.200850910.

[24] A.V. Murueva, E.I. Shishatskaya, A.M. Kuzmina, T.G. Volova, A.J. Sinskey, Microparticles prepared from biodegradable polyhydroxyalkanoates as matrix for encapsulation of cytostatic drug, J. Mater. Sci. Mater. Med. 24 (2013) 1905-1915, https:// doi.org/10.1007/s10856-013-4941-2.

[25] G. Eke, A.M. Kuzmina, A.V. Goreva, E.I. Shishatskaya, N. Hasirci, V. Hasirci, In vitro and transdermal penetration of PHBV micro/nanoparticles, J. Mater. Sci. Mater. Med. 25 (2014) 1471-1481, https://doi.org/10.1007/s10856-014-5169-5.
[26] G.Q. Chen, J. Zhang, Microbial polyhydroxyalkanoates as medical implant biomaterials, Artificial Cells Nanomedicine, and Biotechnology 46 (2018) 1-18, https://doi. org/10.1080/21691401.2017.1371185.

[27] H.S. Barud, J.L. Souza, D.B. Santos, M.S. Crespi, C.A. Ribeiro, Y. Messaddeq, S.J.L. Ribeiro, Bacterial cellulose/poly(3-hydroxybutyrate) composite membranes, Carbohydr. Polym. 83 (2011) 1279-1284, https://doi.org/10.1016/j.carbpol.2010.09.049.

[28] C. Zhijianga, Y. Guanga, J. Kim, Biocompatible nanocomposites prepared by impregnating bacterial cellulose nanofibrils into poly(3-hydroxybutyrate), Curr. Appl. Phys. 11 (2011) 247-249, https://doi.org/10.1016/j.cap.2010.07.016.

[29] E. Akaraonye, J. Filip, M. Safarikova, V. Salih, T. Keshavarz, J.C. Knowles, I. Roy, Composite scaffolds for cartilage tissue engineering based on natural polymers of bacterial origin, thermoplastic poly(3-hydroxybutyrate) and micro-fibrillated bacterial cellulose, Polym. Int. 65 (2016) 780-791, https://doi.org/10.1002/pi.5103.

[30] I. Chiulan, D. Mihaela Panaitescu, A. Nicoleta Frone, M. Teodorescu, C. Andi Nicolae A. Căsărică, V. Tofan, A. Sălăgeanu, Biocompatible polyhydroxyalkanoates/bacterial cellulose composites: preparation, characterization, and in vitro evaluation, J. Biomed. Mater. Res. A 104 (2016) 2576-2584, https://doi.org/10.1002/jbm.a.35800.

[31] C. Zhijiang, X. Yi, Y. Haizheng, J. Jia, Y. Liu, Poly(hydroxybutyrate)/cellulose acetate blend nanofiber scaffolds: preparation, characterization and cytocompatibility, Mater. Sci. Eng. C Mater. Biol. Appl. 58 (2016) 757-767, https://doi.org/10.1016/j. msec.2015.09.048.

[32] S.Y.H. Abdalkarim, H.Y. Yu, M.L. Song, Y. Zhou, J. Yao, Q.O. Ni, In vitro degradation and possible hydrolytic mechanism of PHBV nanocomposites by incorporating cellulose nanocrystal - ZnO nanohybrids, Carbohydr. Polym. 15 ( (2017) 38-49, https://doi.org/10.1016/j.carbpol.2017.08.051.

[34] D.K. Owens, R.C. Wendt, Estimation of the surface free energy of polymers, J. Appl. Polym. Sci. 13 (1969) 1741-1747.

[35] L.N. Popova, How to Change Borders of Epidermis During Wound Healing, Ph.D. Thesis 1942 1-14. 